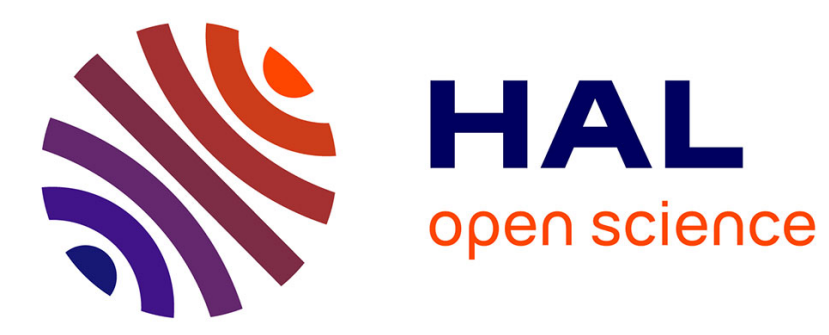

\title{
On the role of Nav1.7 sodium channels in chronic pain: an experimental and computational study
}

Alberto Capurro, Jack Thornton, Bruno Cessac, Lyle Armstrong, Evelyne Sernagor

\section{- To cite this version:}

Alberto Capurro, Jack Thornton, Bruno Cessac, Lyle Armstrong, Evelyne Sernagor. On the role of Nav1.7 sodium channels in chronic pain: an experimental and computational study. 2019. hal02414907

\author{
HAL Id: hal-02414907 \\ https://hal.inria.fr/hal-02414907
}

Preprint submitted on 16 Dec 2019

HAL is a multi-disciplinary open access archive for the deposit and dissemination of scientific research documents, whether they are published or not. The documents may come from teaching and research institutions in France or abroad, or from public or private research centers.
L'archive ouverte pluridisciplinaire HAL, est destinée au dépôt et à la diffusion de documents scientifiques de niveau recherche, publiés ou non, émanant des établissements d'enseignement et de recherche français ou étrangers, des laboratoires publics ou privés. 


\section{On the role of Nav1.7 sodium channels in chronic pain: an experimental and}

\section{computational study}

Alberto Capurro ${ }^{1 *}$, Jack Thornton ${ }^{1}$, Bruno Cessac ${ }^{2}$, Lyle Armstrong ${ }^{1}$, Evelyne Sernagor ${ }^{1}$

1. Biosciences Institute, Faculty of Medical Sciences, Newcastle University, UK.

2. Université Côte d'Azur, Inria, Biovision team, France.

Short title:

Chronic pain and Nav1.7 gating in human nociceptive neurons

* Corresponding author

E-mail: alberto.capurro@newcastle.ac.uk 


\section{Abstract}

2 Chronic pain is a global healthcare problem with a huge societal impact. Its management remains

3 generally unsatisfactory, with no single treatment clinically approved in most cases. In this study we

4 use an in vitro model of erythromelalgia consisting of dorsal root ganglion neurons derived from

5 human induced pluripotent stem cells obtained from a patient (carrying the mutation F1449V) and a

6 control subject. We combine neurophysiology and computational modelling to focus on the Nav1.7

7 voltage gated sodium channel, which acts as an amplifier of the receptor potential in nociceptive

8 neurons and plays a critical role in erythromelalgia due to gain of function mutations causing the

9 channel to open with smaller depolarisations.

10 Using extracellular recordings, we found that the scorpion toxin OD1 (a Nav1.7 channel opener)

11 increases dorsal root ganglion cell excitability in cultures obtained from the control donor, evidenced

12 by an increase in spontaneous discharges, firing rate and spike amplitude. In addition, we confirmed

13 previous reports of voltage clamp experiments concerning an increase in spontaneous discharge in

14 the patient cell cultures and the analgesic effects of the Nav1.7 blocker PF-05089771. Our findings

15 are explained with a conductance-based model of the dorsal root ganglion neuron, exploring its

16 behaviour for different values of half activation voltage and inactivation removal rate of the Nav1.7

17 current. Erythromelalgia was simulated through a decrease of the Nav1.7 half activation voltage, turning previously subthreshold stimuli to pain-inducing, and successfully counteracted with the channel blocker. The painful effects of OD1 were simulated through a quicker removal of Nav1.7 inactivation that reproduced the effects of the toxin not only on the spike frequency but also on its amplitude.

\section{New \& Noteworthy}

23 We investigate Nav1.7 channel gating mechanisms in human iPSC-derived dorsal root ganglion cell

24 cultures using multielectrode array recordings. The scorpion toxin OD1 increases firing frequency

25 and spike amplitudes whilst the analgesic PF-05089771 decreases or even abolishes spontaneous 
activity. The antagonistic effect of these compounds is explained with a computational model to

reach deeper understanding of changes in channel kinetics in erythromelalgia, a chronic pain disorder.

\section{Introduction}

30 Chronic pain is a global healthcare problem, particularly affecting elderly people, women and persons with lower socio-economic status (Van Hecke et al., 2013). It is one of the most common reasons for physician consultation in developed countries, interfering with quality of life and causing large socio-economic impacts that include significant loss of working hours and the need of clinical care. Current therapies have limitations in their effectiveness and side effects, creating an urgent need to develop more precise and effective treatments for pain management (Khouzam, 2000). In this study we focus on the voltage dependent properties of the sodium channel Nav1.7 that is implicated in inherited erythromelalgia, a vascular peripheral pathology causing attacks of severe chronic pain (McDonnell et al., 2016).

Pain evoked spiking activity starts in peripheral terminals of dorsal root ganglion (DRG) neurons. The central extensions of these neurons form the $A \delta$ and $C$ fibres which establish glutamatergic synapses onto second order neurons within the spinal cord. They can be stimulated by mechanical, thermal or chemical stimuli as well as by inflammatory mediators. Distributed throughout the body (skin, viscera, muscles, joints, meninges), they carry noxious sensory information into the central nervous system (Serpell, 2006). The recent discovery of nociceptive Schwann cells has changed the notion of bare nerve terminals being the starting point of pain sensation, and introduced the concept of a glioneural end organ in the skin that transmits nociceptive information to the nerve, resembling the specialized receptor cells found in other sensory systems (Abdo et al., 2019). 
51 reason it is considered to be a threshold channel that acts as an amplifier of the receptor potential,

52 increasing the probability of triggering a spike via the activation of other, higher threshold sodium

53 channels such as Nav1.8. This amplification property makes Nav1.7 a major contributor to pain

54 signalling in humans (Dib-Hajj et al., 2013).

55 Erythromelalgia is caused by gain? of? function mutations of the gene SCN9A, which encodes for the

56 Nav1.7 channels pain (McDonnell et al., 2016). Different types of mutations have in common the

57 need for less depolarization to open the channel than in the wild type, resulting in a decrease of the

58 rheobase (i.e., minimal amplitude of an infinite depolarizing current to evoke a spike) (Cao et al.,

59 2016). DRG neurons fire spontaneously in erythromelelgia patients, although normally these cells

60 are silent unless receiving strong peripheral pain stimulus.

61 In this study, we have used extracellular recordings of spontaneous activity in DRG neuron cultures

62 derived from human induced pluripotent stem cells (hiPSCs) obtained from an erythromelalgia

63 patient and a control subject to study the voltage dependent gating properties of Nav1.7 channels.

64 To start, the effects on the neuronal firing of two different pharmacological compounds -a pain

65 eliciting scorpion toxin (OD1, Motin et al., 2016) and an analgesic drug (PF-05089771, Cao et al.,

66 2016)- were assessed in these cultures using multi electrode array (MEA) recordings. We then

67 present a simple conductance-based computational model of the DRG neuron to explain our findings

68 in terms of the Nav1.7 gating process, focusing on the channel activation (opening) and repriming

69 (i.e., recovery from inactivation).

\section{Materials and Methods}

\section{Cells and MEA recordings}

72 For this study we used hiPSCs from a control subject (cell line AD3) and an erythromelalgia patient

73 (cell line RCi002-A, carrying the mutation F1449V) made available at the European Bank for induced

74 pluripotent stem cells (EBiSC). The cells were differentiated into sensory neurons using a small 
molecule based protocol described previously (Cao et al., 2016, and references therein). Once they

reached the stage of DRG neurons, the cells were re-plated in 24 wells MEA plates (MEA700,

Multichannel Systems, Reutlingen, Germany) where the spontaneous activity was recorded after 10

pitch), making a total of 288 electrodes per plate. The large distance between electrodes makes it

We compared the spontaneous activity of DRG neurons obtained from a control subject (plated in 18 wells, making a total of 216 electrodes in MEA 1) with an erythromelalgia patient (plated in 24 wells, making a total of 288 electrodes in MEA 2). In addition we used a third MEA plated with diseased cells stimulated with higher concentration of potassium (from $4.16 \mathrm{mM}$ in the growing medium to $6 \mathrm{mM}$ ) to enhance spontaneous activity (plated in 24 wells, making a total of 288 electrodes in MEA 3). This allowed us to find more active neurons following the addition of PF05089771 to make paired comparisons before and after this treatment that tends to suppress the firing in many channels. Each well constitutes an independent cell culture. (100 nM) in the patient (MEAs 2 and 3). The activity was recorded for 5 minutes immediately before the application of each substance and compared with a recording of the same duration performed 5 minutes after the onset of drug exposure. Wells contained $200 \mu \mathrm{l}$ of growing medium and $5 \mu \mathrm{l}$ drops were added to apply the treatments. The experimental doses were selected to be in a near 
bioRxiv preprint first posted online Dec. 11, 2019; doi: http://dx.doi.org/10.1101/871236. The copyright holder for this preprint

(which was not peer-reviewed) is the author/funder, who has granted bioRxiv a license to display the preprint in perpetuity.

All rights reserved. No reuse allowed without permission.

99

100

101

102

103

104

105

106

107

108

109

110

111

112

113

114

115

116

117

118

et al., 2016 for PF-05089771; Motin et al., 2016 for OD1). Both compounds were purchased from Tocris (Bio-Techne, Abingdon, UK).

\section{Spike sorting and pairing of units}

Recordings were performed with the Multiwell-MEA-System and the software Multi Channel Experimenter (Multi Channel Systems, Reutlingen, Germany). Each channel was band-pass filtered (100 to $3500 \mathrm{~Hz}$ ) and acquired with a sampling rate of $20 \mathrm{kHz}$.

The raw voltage traces were first plotted and inspected using a zoom tool to discard artefacts and confirm the existence of spikes. The voltage time series were then fed into the Matlab toolbox Waveclus (Quian Quiroga et al., 2004) to perform spike sorting in all active channels. In the toolbox, the continuous data were filtered again with a non-causal band pass filter between 300 and $3000 \mathrm{~Hz}$ and the firing times were detected with an amplitude threshold. We used a dual threshold (i.e., picking deflections in both up and down directions) set to 5 median absolute deviations of the filtered voltage signal with a refractory period of $2 \mathrm{~ms}$ to avoid double annotations due to fast voltage oscillations in the vicinity of the threshold. Spikes were aligned to their maximum, after interpolating the waveforms to locate the peak time more accurately. The toolbox uses a wavelet based method for feature extraction, and the grouping of spikes into clusters is done with superparamagnetic clustering (Blatt et al., 1996), a stochastic algorithm that does not assume any particular distribution of the data. In few cases the dual threshold created mistakes in the detection, so we decided to use a single threshold, kept for the units that corresponded to the same neuron before and after a given treatment. We consider this spike sorting strategy as supervised, always following the criterion of the biologist as ground true. The firing times and voltage cut outs of all units were stored to document the parameters and quality of the spike sorting in each channel.

Units that were active both before and after each pharmacological treatment were identified. The only set-in-stone criterion for deciding if they are the same cell is the coordinates of the current sources, using high density MEAs (Hilgen et al., 2017). As our data were recorded with low density 
124 MEAs, we cannot provide this level of certainty, but assumed that they corresponded to the same

125 neuron if the wave shape remained similar across recordings performed within few minutes of each

126 other. Possible ambiguities were minimized by the fact that most channels yielded only one or two

127 active neurons. These pairs were used to investigate the changes in spike frequency and amplitude

128 caused by the pharmacological treatments (Figs 1 and 2). If we were reasonably convinced that a

129 given unit corresponded to the same neuron before and after treatment, we designated the two

130 recordings as a pair. In the case of the control cultures, few neurons had spontaneous discharges

131 and most cells started to fire only after the OD1 treatment. Conversely, in the case of the patient

132 cultures, several neurons were active before, but few remained active after the application of PF-

133 05089771. In that case, we made an additional recording after increasing the spontaneous activity

134 with potassium, as mentioned above. This manipulation allowed to get more active neurons in

135 control conditions, and then more neurons remained active after the treatment to configure pairs,

136 although we did not pool the data recorded with and without higher potassium concentration.

137 For statistical comparisons between two conditions we used the Wilcoxon signed rank test (for 138 paired values) or the Mann-Whitney $\mathrm{U}$ test (for unpaired values). We also used cross correlation 139 histograms of the spike times recorded from the same channel to assess whether neurons tend to 140 fire at fixed delay from another.

\section{$141 \quad$ Numerical simulations}

142 We performed numerical simulations of the membrane potential and sodium channels gate parameters of a single DRG neuron using the software NEURON (www.neuron.yale.edu), e.g., Choi et al., 2011). The integration method was the IDA algorithm (e.g., Carnevale, 2007) with a fixed time step of $0.025 \mathrm{~ms}$ (i.e., 40 time steps per ms). Our purpose is to explain the changes in frequency and amplitude induced by the drug treatments covered in the previous section. In this context we

147 adopted a parsimonious approach to keep the model as simple as possible, using Hodgkin and 148 Huxley (HH) type of $\mathrm{Na}^{+}$and $\mathrm{K}^{+}$currents (Ermentrout and Terman, 2010) with parameters (Table 1) 
adapted to be plausible for mammal cells (Krouchev et al., 2015) plus a single Nav1.7 type current added using the Channel Builder GUI (McDougal et al., 2017).

The two different types of sodium channels that we included differed only in their parameters (Table activating/inactivating rates and a more depolarized value of half inactivation voltage removal than the HH type channel (Table 1). These changes allowed to create a rapidly activating but slowly repriming (slow recovery from inactivation) current, resembling Nav1.7. To simulate erythromelalgia we varied the half activation voltage of Nav1.7 from -55 to $-60 \mathrm{mV}$. To simulate PF-05089771 effect, we varied the maximum conductance of Nav1.7 from 0.1 to $0.07 \mathrm{~S} / \mathrm{cm}^{2}$ (Figs 3 and 4 ) and to simulate OD1 effects (Figs 5, 6 and 7) we increased 10 times the parameter $A_{h}$ that multiplies the inactivation removal rate $a_{h}$. Model parameters are provided in Table 1 , the equations that are most relevant for our results appear in section Results and all model equations are listed in S1 Appendix.

Step depolarisations of $0.04 \mathrm{nA}$ lasting $60 \mathrm{~ms}$ were used to evaluate the effect of the half activation voltage $\left(d_{h}\right)$ and the inactivation removal rate $\left(a_{h}\right)$ on the firing frequency of the spike (Figs 3 and 5 ). depolarization steps lasting $5 \mathrm{~s}$ (Figs 4 and 6).

In order to assess for bifurcations in the dynamical system, we performed simulations of the maximum and minimum values of the voltage oscillation as a function of the amount of external current injected (i.e., a one dimensional bifurcation diagram, e.g., Fig 3 in Doi et al., 2001, for $d_{m}=-$ $58 \mathrm{mV}$ and $g_{\max }=0.1 \mathrm{~S} / \mathrm{cm}^{2}$. 
bioRxiv preprint first posted online Dec. 11, 2019; doi: http://dx.doi.org/10.1101/871236. The copyright holder for this preprint

(which was not peer-reviewed) is the author/funder, who has granted bioRxiv a license to display the preprint in perpetuity.

All rights reserved. No reuse allowed without permission.

173 All figures of the article were created with Matlab (R2018b, The MathWorks, Inc., Natick,

174 Massachusetts, United States) and finalized with Adobe illustrator (Adobe Inc.).

\section{Results}

176 Experimental recordings

177 We compared the spontaneous activity of DRG neurons obtained from a control subject (cell line

$178 \mathrm{AD} 3, \mathrm{n}=18$ cultures) with an erythromelalgia patient (cell line RCi002-A, $n=24$ cultures). The 179 percentage of electrodes showing activity was $1.85 \%$ in the control and $5.9 \%$ in the disease 180 cultures. After spike sorting we found 30 spontaneously active units in the patient and only 7 in the control. The firing frequency and amplitude of these units were not significantly larger in the disease cultures, implying that although much more units are active, they do not necessarily fire faster or have spikes of larger amplitude. It is worth mentioning that the fastest neurons and the tallest spikes were found in the disease cultures, but the distributions were not significantly different because slow units with small amplitude were present in both groups. The larger number of spontaneously active neurons found in the disease cultures is consistent with the results of a previous study (Cao et al., 2016).

The cultures from the control subject were treated with OD1 (100 nM), resulting in the percentage of active channels increasing from 1.85 to $6.02 \%$ and a concomitant increase in the number of active units, from 7 to 24 . An example of the voltage data before and after treatment is presented in Fig 1A, note the large increase in spontaneous activity. The same picture was observed in an erythromelalgia culture conducted just as a verification (not shown).

193 Pairing all the units that were active before and after OD1 application in the control cells $(n=7)$, we 194 found that both the spike frequency and amplitude increased significantly (Fig 1-B). Although the 195 increase in amplitude was not dramatic ( $20 \%$ in average), it was consistently found in every pair of 196 units. The extent of the increase in firing frequency was more pronounced $(70 \%)$. The unpaired units 
that were initially silent and started to fire after the OD1 were not significantly different in rate and amplitude from those already active before the treatment.

The cells from the patient were treated with PF05089771 (100 nM). The percentage of channels with

Pairing the units that were active before and after the treatment $(n=6)$, we found that the spike frequency decreased significantly but the amplitude did not change (Fig 2-B). This result was confirmed with a larger number of paired units $(n=16)$ in a MEA plate previously exposed to high potassium concentration (Fig 2-C). In both cases the unpaired units that stopped firing as a result of the PF05089771 application were not significantly different in rate and amplitude to the ones that remained active after treatment.

In order to assess for possible functional connectivity, we calculated cross correlation histograms between the firing times of the neurons that were recorded from the same electrode. No histogram peaks at fixed latency were found, which is compatible with the established notion that DRG neurons do not form synaptic contacts between them.

\section{Numerical simulations}

In this subsection we present the results obtained with the computational model of the single DRG neuron explained in section Methods, including the equations directly related with the quantities plotted in the figures. The equations of all currents are provided in S1 Appendix.

Our DRG neuron was simulated as a cylindrical soma of $30 \mu \mathrm{m}$ diameter and height. The ionic conductances are based on a $\mathrm{HH}$ model with mammalian-plausible parameters plus an additional 
bioRxiv preprint first posted online Dec. 11, 2019; doi: http://dx.doi.org/10.1101/871236. The copyright holder for this preprint (which was not peer-reviewed) is the author/funder, who has granted bioRxiv a license to display the preprint in perpetuity.

All rights reserved. No reuse allowed without permission.

erythromelalgia patients, this parameter is shifted up to $15 \mathrm{mV}$ in hyperpolarizing direction (Cao et

$\begin{array}{lr}\text { General parameter set } \\ \mathrm{L}(\mu \mathrm{m}) & 30 \\ \mathrm{~d}(\mu \mathrm{m}) & 30 \\ \mathrm{~cm}\left(\mu \mathrm{F} / \mathrm{cm}^{2}\right) & 1 \\ \text { gNa_hh }\left(\mathrm{S} / \mathrm{cm}^{2}\right) & 0.3 \\ \text { gNav1.7_hh }\left(\mathrm{S} / \mathrm{cm}^{2}\right) & 0.1 \\ \text { gK_hh }\left(\mathrm{S} / \mathrm{cm}^{2}\right) & 0.15 \\ & 3.00 \mathrm{E}- \\ \text { gL_hh }\left(\mathrm{S} / \mathrm{cm}^{2}\right) & 05 \\ \text { eL_hh (mV) } & -65 \\ \text { eK (mV) } & -90 \\ \text { eNa (mV) } & 60 \\ \text { Initial V (mV) } & -75 \\ \text { dt (ms) } & 0.025 \\ \text { Temp (Celsius) } & 37\end{array}$

\section{$\mathrm{Na} \mathrm{HH}$ parameters}

Opening $\left(a_{m}\right)$

$A\left(m s^{-1}\right)$

$\mathrm{k}\left(\mathrm{ms}^{-1}\right)$

$\mathrm{d}(\mathrm{mV})$

Closing $\left(b_{m}\right)$

$A\left(m s^{-1}\right)$

$k\left(m s^{-1}\right)$

$-0.055$

$\mathrm{d}(\mathrm{mV})$

Inactivation removal $\left(a_{h}\right)$

$\mathrm{A}\left(\mathrm{ms}^{-1}\right)$

0.07

$\mathrm{k}\left(\mathrm{ms}^{-1}\right)$

$-0.05$

$\mathrm{d}(\mathrm{mV})$

Inactivation establishment $\left(b_{h}\right)$

$\mathrm{A}\left(\mathrm{ms}^{-1}\right)$

$\mathrm{k}\left(\mathrm{ms}^{-1}\right)$

$\mathrm{d}(\mathrm{mV}$

\begin{tabular}{l|r}
\hline K HH parameters & \\
Opening $\left(a_{m}\right)$ & 0.1 \\
$\begin{array}{l}A\left(m s^{-1}\right) \\
k\left(m s^{-1}\right)\end{array}$ & 0.1 \\
$d(m V)$ & -55 \\
Closing $\left(b_{m}\right)$ & \\
$A\left(m s^{-1}\right)$ & 0.125 \\
\hline$k\left(m s^{-1}\right)$ & -0.0125 \\
$d(m V)$ & -65 \\
\end{tabular}

\section{Nav1.7 parameters}

Opening $\left(a_{m}\right)$

$A\left(m s^{-1}\right)$

13.78

$k\left(m s^{-1}\right)$

0.1

$\mathrm{d}(\mathrm{mV})$

$-58$

Closing $\left(b_{m}\right)$

$A\left(m s^{-1}\right)$

55.11

$\mathrm{k}\left(\mathrm{ms}^{-1}\right)$

$-0.055$

$\mathrm{d}(\mathrm{mV})$

$-65$

Inactivation removal $\left(a_{h}\right)$

$A\left(m s^{-1}\right)$

0.92

$\mathrm{k}\left(\mathrm{ms}^{-1}\right)$

$-0.05$

$\mathrm{d}(\mathrm{mV})$

$-40$

Inactivation establishment $\left(b_{h}\right)$

$\mathrm{A}\left(\mathrm{ms}^{-1}\right)$

8.76

$\mathrm{k}\left(\mathrm{ms}^{-1}\right)$

$-0.1$

$\mathrm{d}(\mathrm{mV})$ 
226 Table 1. Default parameter values used for the simulations. Particular cases are indicated in the 227 corresponding figures.

228 The rate of Nav1.7 channel opening $a_{m}$ is given by

$229 \quad a_{m}=\frac{A_{m}\left(k_{m}\left(v-d_{m}\right)\right)}{1-e^{-k_{m}\left(v-d_{m}\right)}}$

230 where $v$ is the membrane potential, $d_{m}$ is the half-activation voltage, and $k_{m}$ and $A_{m}$ are constants

231 (Table 1). The opening and closing dynamics of the current is given by the differential equation

$232 \quad \frac{d m}{d t}=a_{m}(1-m)-b_{m} m$

233 where $m$ is the opened state of the channel, 1- $m$ the closed state and $b_{m}$ the closing rate.

234 The conductance is a cubic function of $m$,

$235 g_{\text {Nav1.7 }}=g_{\max } m^{3} h$

where $h$ is the inactivation process and $g_{\max }$ the maximum conductance.

In Fig 3 we show the effects of varying $d_{m}$ (Equation 1 ) in the model neuron by displaying the response to a depolarizing current step of $0.04 \mathrm{nA}$ lasting $60 \mathrm{~ms}$. This level of current is slightly above the firing threshold at $d_{m}=-58 \mathrm{mV}$ and $g_{\max }=0.1 \mathrm{~S} / \mathrm{cm}^{2}$, which is $0.037 \mathrm{nA}$. At this threshold the one dimensional bifurcation diagram (not shown) presents a discontinuity that corresponds to a Hopf bifurcation (see section Discussion). The upper blue trace represents a normal subject $\left(d_{m}=-55 \mathrm{mV}\right)$ where the stimulus does no elicit pain (i.e., no spiking). The pink traces of the middle row represent mild erythromelalgia $\left(d_{m}=-58 \mathrm{mV}\right)$ where the same stimulus is painful (spiking in the left panel) and can be successfully treated by blocking $20 \%$ of the Nav1.7 channels, i.e., decreasing the maximum conductance $\left(g_{\max }\right.$ in Equation 3) from 0.1 to $0.08 \mathrm{~S} / \mathrm{cm}^{2}$ (no spiking in the right panel). In the red traces of the lower row we simulate severe erythromelalgia $\left(d_{m}=-60 \mathrm{mV}\right)$, showing faster spiking rate (left) and spontaneous spikes occurring before and after the stimulus. In this case, blocking $20 \%$ 
249 firing can be stopped by blocking a larger percentage of Nav1.7 channels $\left(30 \%\right.$ with $g_{\max }=0.07$

$250 \mathrm{~S} / \mathrm{cm}^{2}$, right panel).

251 In Fig 4 we provide a qualitative frame to understand the situations described in the previous figure.

252 Using a heat map, the spike rate of the neuron model (stimulated with $0.04 \mathrm{nA}$ depolarizing current)

253 is represented with a color bar for different values of maximum conductance $g_{\max }$ (Equation 3,

254 abscissas) and half activation voltage parameter $d_{m}$ (Equation 1, ordinates) of the Nav1.7 current.

255 The white circles with numbers on the heat map indicate the coordinates $\left(g_{\max }\right.$ and $\left.d_{m}\right)$ used for the

256 simulations depicted in Fig 3. The numbers inside the circles of Fig 4 correspond to the numbers in

257 the panels of Fig 3. Erythromelalgia mutations cause pain through a downward shift toward the red

258 values of the heat map (e.g., trajectories 1 to 2 and 2 to 4). Conversely, the treatment with Nav1.7

259 blockers (e.g., PF05089771) alleviates pain through a shift to the right, towards the blue values (e.g.,

260 trajectories 2 to 3 and 4 to 5 and 6$)$.

261 In a second series of simulations we explored the inactivation properties of Nav1.7 channels

262 (parameter sets displayed in Table 1). The scorpion toxin OD1 has been reported to increase the rate

263 at which Nav1.7 inactivation is removed after being established (Motin et al., 2016). In order to

264 emulate this effect in the model, we increased 10 times the removal rate of Nav1.7 inactivation ( $a_{h}$

265 in Equation 4).

266 The inactivation removal rate is given by

$267 \quad a_{h}=A_{h} e^{k_{h}\left(v-d_{h}\right)}$

268 where $v$ is the membrane potential, $k_{h}$ and $A_{h}$ are constants (Table 1 ) and $d_{h}$ is the half-inactivation

269 removal parameter. The inactivation process dynamic is given by the temporal derivative of $h$

$270 \quad \frac{d h}{d t}=a_{h}(1-h)-b_{h} h$

where $1-h$ is the inactivated state and $h$ is the non-inactivated state that allows ionic conduction. 
272 To increase $a_{h}$ we increased the multiplicative constant $A_{h}$ by 10 times (Equation 4). This change

273 caused the model neuron to fire in response to a depolarizing pulse of $0.04 \mathrm{nA}$ that was not effective

274 before (upper panels in Fig 5) and elicited a faster firing rate if the neuron was already active in the 275 control condition (lower panels in Fig 5).

276 The faster removal of Nav1.7 inactivation $\left(A_{h}\right.$ varied from 0.92 to 9.2$)$ also increased the model spike 277 amplitude to a moderate amount in the simulation after OD1 (red plot in Fig 6), as observed in the 278 extracellular recordings (Fig 1-B). In Fig 7-A, we show plots of $m$ (thin full lines) and $h$ (dashed lines) 279 during a spike, in a simulation before (blue plots of left panel) and after OD1 (red plots of right 280 panel). Both panels display the Nav1.7 current with full thick lines. Note that in the simulation after 281 OD1, Nav1.7 has larger amplitude, and the values of $h$ are higher, with a faster return to 1 after the 282 negative peak. These large changes of $h$ were not observed in the $\mathrm{HH}$ type high threshold sodium 283 current, although the current amplitude was slightly increased (Fig 7-B).

284 Discussion

In this study, we performed to our knowledge the first test of the scorpion toxin OD1 in hiPSCderived DRG neurons. This toxin enhances the recovery from fast inactivation of the threshold current Nav1.7 (Motin et al., 2016). Our extracellular recordings also confirmed previous findings of Cao et al. (2016) with patch clamp regarding the increased spontaneous firing of erythromelalgia DRG cells and the analgesic effects of PF-05089771. This drug was shown to be clinically effective to control heat induced pain attacks by stabilizing the voltage sensor domain of the Nav1.7 channel in a non-conducting conformation. The effects of both compounds were explained using a conductancebased computational model, comparable with Choi et al. (2011) but simpler and particularly focalized on the issue of pain signalling. In this section we first discuss our main findings and emphasize the usefulness of extracellular recordings to observe changes in ionic currents. To close different sodium currents in erythromelalgia. 
298 Cao et al. (2016) performed voltage clamp experiments in whole-cell configuration in DRG cells derived from erythromelalgia patients and control subjects. Despite the heterogeneity of the samples, they found a significantly higher proportion of spontaneously firing cells in patients compared to those from control donors. Moreover, the patient's cells showed a lower rheobase and reached higher firing rates in response to stimulation with current steps of increasing amplitudes. These findings point to the existence of elevated excitability in erythromelalgia cells, a fact that we confirmed in the present study by showing higher prevalence of spontaneous activity in extracellular MEA recordings (section Results).

Spontaneous firing in our cultures is due only to intrinsic cell excitability, as there are no reports about the formation of synapses between DRG cells in vitro. Accordingly, we did not find evidence of functional connections in cross correlation histograms between neuronal firing times. Furthermore, in dissociated cell cultures the development of a synaptic network is usually accompanied by the emergence of population bursts (Maeda et al., 1995) which we did not observe here. DRG glia cells are not present in the cultures, so their reported contribution to abnormal neuronal activity in in vitro studies done on intact DRG (Belzer and Hanani, 2019) can also be ruled out.

Regarding the effects of Nav1.7 channel blockers, Cao et al. (2016) reported a dose dependent reduction in spontaneous firing and an increase in the action potential rheobase. We were able to reproduce the first finding on spontaneous firing with PF-05089771 (Fig 2), supporting the fact that the excitability of the cells plummets after the treatment, in accordance with the reported clinical efficacy of the drug (Cao et al., 2016). We did not, however, observe significant changes in spike amplitudes before and after drug treatment. 
the decay phase of the Nav1.7 channel opening slows down in a concentration-dependent manner

323 in the presence of these toxins. Using a paired-pulse protocol in the voltage clamp configuration, the

324 authors demonstrated an enhancement of Nav1.7 recovery from fast inactivation. Single channel

recordings showed that the mean open time of the channels was not substantially changed by the

toxin, but the channels exhibited a prolonged flickering behavior between open and closed states,

which enabled a more efficient inactivation removal. These experiments pointed to a voltage-sensor

trapping interpretation, in which the toxin prevents a conformational change in the domain IV

voltage sensor, as the main cause for the observed prolongation in the current duration. Motin et al.

(2016) also found that the current-voltage relationships of Nav1.7 are shifted to more negative

potentials in the presence of OD1, but this effect has a small magnitude $(-3 \mathrm{mV})$, in accordance with

earlier observations in Xenopus laevis oocytes with Nav1.7 channels expression (Maertens et al.,

2006).

Our findings corroborate those of Motin et al. (2016). Indeed, we observed an increase in the

proportion of electrodes showing spontaneous firing in the presence of OD1, as well as an increase

in firing rate in cells that did fire before adding the toxin. In addition to the firing frequency rise, we

found a consistent increase in the spike amplitude after OD1, in contrast with the PF-05089771

treatment which affected only the firing rate. These larger extracellular spikes are in accordance

with the increase in peak current observed in the presence of OD1 in voltage clamp experiments

340 (Maertens et al., 2006; Motin et al., 2016). Since the amplitude of the current generated by the opening of a single channel was not modified by OD1 (Motin et al., 2016), the size increase of the extracellular spikes must be due to the dynamics of the gating process. In the next section, we amplitude described above. 
346 The computational model that we present here is able to provide satisfactory explanations at a

347 qualitative level for the main experimental findings of our study and for previous studies on 348 erythromelalgia and the effects of pharmacological manipulations on Nav1.7 channels. We did not 349 attempt to perform a complete exploration of the parameter space but all values are biologically 350 plausible. In the absence of stimulation the membrane potential tends to its fixed point which is the resting potential. By injecting an amount of current also plausible for a patch clamp experiment (0.037 nA for $d_{m}=-58 \mathrm{mV}$ and $\left.g_{\max }=0.1 \mathrm{~S} / \mathrm{cm}^{2}\right)$, the system reaches a Hopf bifurcation (e.g., and from 4 to 5 and 6 depict the analgesic path triggered by PF-05089771.

While the decrease of Nav1.7 maximum conductance accounted for the analgesic effects of PF05089771, OD1 effects on the firing rate were reproduced by enhancing the constant governing the removal rate of the inactivation $a_{h}$ (Fig 5). The interpretation of these results is quite straight forward, having fewer available Nav1.7 receptors reduces the firing by interfering with the amplification of subthreshold potentials performed by the channel, while the faster inactivation removal increases the current size and duration (Fig 7), leading to increased spiking and excitability. intense pain known to be experienced after a scorpion sting (e.g., Garfunkel et al., 2007). 
maximum amplitude that a spike can potentially reach in the absence of inactivation is given by the sodium equilibrium potential. The inactivation process will also limit the maximum value reached by the current and the peak intracellular voltage, because the current starts to inactivate before the opening process is completed. If this reasoning is correct, an increase of the inactivation removal rate of Nav1.7 will create a larger spike, because more channels will be free from inactivation during the critical period of the spike rising phase.

This last interpretation is exemplified in the numerical simulations of Figs 6 and 7. The consequences

of the faster inactivation removal rate of Nav1.7 after OD1 are noticeable in the higher values of the

process $h$, as well as in its faster return to 1 following the negative peak. The closer to $0 h$ reaches,

the more channels are inactivated, so a larger $\mathrm{h}$ value implies more open channels potentially available, which is reflected in a larger Nav1.7 current (Fig 7-A). The high threshold $\mathrm{Na}^{+}$current also pronounced than for Nav1.7, but still contributes to increase the spike size because the total $\mathrm{HH}$ type current is bigger. We must keep in mind that the extracellular spike is a filtered version of the intracellular spike and we cannot necessarily compare the amplitude differences linearly. In addition,

Nav1.7 and Nav1.8 interact in a complex manner to regulate DRG neuronal excitability, as has been shown in a previous modelling study of the rat HRV neurons (Choi and Waxman, 2011). Despite these caveats, we can assume that in the situation depicted in our simulation both currents are adding up to enhance the intracellular spike (Fig 6). This effect was captured in our extracellular recordings (Fig 1).

\section{Model limitations}

We are interested in understanding the reason for the observed changes in spike rate and amplitude 
396 for all variables, we opted for a modified HH scheme, which also has the virtue of being familiar to 397 neurobiologists. We included only one potassium current (non-inactivating, HH type), to avoid unnecessary complexity. The only added current to the original HH scheme is the Nav1.7, because it

is strictly needed to implement the biological mechanisms under consideration. A detailed quantitative modelling would require $\mathrm{Ca}^{2+}$ currents and several types of $\mathrm{Na}^{+}$and $\mathrm{K}^{+}$currents that

Waxman, 2011; Newberry et al., 2016; Mandge and Manchanda, 2018; Zemel et al., 2018), and is

beyond the scope of this study. Although more refined kinetic models of the Nav1.7 sodium and

other channels have been proposed (e.g., Sigg, 2014), we think that we are adopting here a level of simplification in the modelling process that is fitted for our purpose.

\section{Extracellular recordings and ionic currents}

407 Although extracellular recordings are typically used to detect firing times, they also have the theoretical ability to report about what are considered to be intracellular features of the action potential (Gold et al., 2006). We want to highlight this possibility of using extracellular recordings to detect changes in ionic currents. If researchers first evaluate them together with voltage clamp data for validation purposes, they can then benefit from the opportunity to observe more neurons simultaneously. A small amplitude change of the DRG neuron spike might not play an important physiological role in pain signalling, which is mainly conveyed by the spike rate, but we provided here a proof of principle regarding the footprint of a current in the extracellular spike.

The fact that the extracellular spike did not show large changes in waveform shape with the treatments (only scaling up moderately with OD1) facilitated our analysis, allowing reasonable assumptions regarding neuron identities before and after the treatments, but this might not be the 
421 it makes sense to speculate about the possibility that, if a larger spike could elicit more

422 neurotransmitter release, then the spike amplitude would also contribute to pain signalling by

423 eliciting a discharge of higher frequency in the ascending spinal neurons.

\section{Importance of the interaction between sodium currents}

425 The interaction between sodium currents can have profound functional consequences, and the

426 clinical signs of erythromelalgia provide a striking example (Rush et al., 2006). As explained above, in

427 pain pathways Nav1.7 increases neuronal excitability mainly by amplifying the depolarization caused

428 by peripheral stimuli, allowing to trigger Nav1.8. This facilitates firing and pain, an effect that is 429 exaggerated in erythromelalgia patients. A key property for this firing to occur (as implemented in 430 our model) is that Nav1.8 does not inactivate until the voltage is quite high (e.g., around $-35 \mathrm{mV}$ ). In 431 the sympathetic nervous system the situation is different because there are no Nav1.8 channels and 432 spikes are sustained by other sodium currents that inactivate at lower voltage (Rush et al., 2006).

433 Then, the excessive depolarization created by a mutated Nav1.7 in erythromelalgia can be sufficient 434 to trigger inactivation, terminating the firing. The excessively active mutated Nav1.7 increases firing 435 in HRV nociceptive neurons but blocks firing in the sympathetic nerves that mediate the contraction 436 of peripheral blood vessels. This results in excessive vasodilatation, creating the typical sign of red 437 extremities that originated part of the name to the disease (erythromelalgia could be translated as 438 "red neuralgia of the extremities"). The importance of the interaction between sodium currents is 439 highlighted by this example, because the same mutation produces opposite effects in the firing of 440 pain afferents and autonomic motor neurons.

\section{$441 \quad$ Figure captions}

442 Fig 1. Effects of OD1 in nociceptive neurons. (A) Voltage data of the most active channel in MEA 1 443 before (upper panel) and after (lower panel) OD1 (100 nM) application. Note the increase in rate 444 and amplitude of the spontaneous activity. (B) Rate and amplitude of paired neurons before and 445 after OD1 (100 nM) application. Corresponding pairs in both plots are color coded. Wilcoxon signed 
rank test $p$ values are printed in each panel. The normalized changes of both indexes are highly correlated $(r=0.78)$.

Fig 2. Effects of PF05089771 in nociceptive neurons. (A) Example of voltage data before and after PF05089771 (100 nM). $\mathrm{K}^{+}$concentration was $6 \mathrm{mM}$. (B) Rate and amplitude of the neurons paired before and after treatment. $\mathrm{K}^{+}$concentration was $4.16 \mathrm{mM}$. (C) Same as in B with a $\mathrm{K}^{+}$concentration of $6 \mathrm{mM}$. Wilcoxon signed rank test $p$ values are printed in panels $B$ and $C$, corresponding pairs are colour coded. The normalized changes in both indexes are poorly correlated $(r=0.21$ in $B$ and 0.53 in C).

Fig 3. Erythromelalgia and PF05089771 effects: simulation of membrane voltage. Response of the model neuron to a $60 \mathrm{~ms}$ depolarizing pulse of $0.04 \mathrm{nA}$ for three different values of half activation voltage $d_{m}$ (in $\mathrm{mV}$ ) and maximum conductance $g_{\max }\left(\right.$ in $\mathrm{S} / \mathrm{cm}^{2}$ ). The numbers with circles in the panels correspond to the numbers inside the white circles of Fig 4.

Fig 4. Erythromelalgia and PF05089771 effects: heat map of the spiking activity. The neuron model spike rate is represented (color bar) for different values of maximum conductance $g_{\max }$ (abscissas) and half activation voltage parameter $d_{m}$ (ordinates) of the Nav1.7 current. The numbers in the white circles correspond to the numbers in the panels of Fig 3 . The dashed line on top indicates an axis break.

Fig 5. Simulation of OD1 effects on the spike rate. Response to a $60 \mathrm{~ms}$ depolarizing pulse of 0.04 nA before (blue plots in left panels) and after (red plots in right panels) a 10 fold increase in the inactivation removal rate $a_{h}$ to simulate OD1 treatment. The value of $d_{m}$ was varied from $57.8 \mathrm{mV}$ (upper panels) to $58 \mathrm{mV}$ (lower panels), while $A_{h}$ was varied from 0.92 (left panels) to 9.2 (right panels).

Fig 6. Simulation of OD1 effects on the spike amplitude. Spikes with different removal rates of Nav1.7 inactivation (parameter $A_{h}=0.92$ in blue plot and 9.2 in red plot, with $d_{m}=-58 \mathrm{mV}$ ). The red spikes are slightly taller than the blue spikes ( $7 \%$ average amplitude increase in a $5 \mathrm{~s}$ simulation). 
471 Fig 7. Simulation of OD1 effects on $\mathrm{Na}^{+}$currents and their gating variables. Values of $m$ (thin full

472 lines), $h$ (dashed lines) and $\mathrm{Na}^{+}$currents (thick full lines) during a spike. The currents were plotted in

$47310 \times \mathrm{S} / \mathrm{cm}^{2}$ and sign inverted for scale display purposes, as $m$ and $h$ always range from 0 to 1 . $A_{h}$ (in

474 Nav1.7 only) was set to 0.92 in the blue plots (simulation before OD1) and to 9.2 in the red plots

475 (simulation after OD1). (A) Nav1.7, note the higher $h$ values after OD1. (B) High threshold $\mathrm{Na}^{+}$

476 current, note that $h$ is similar before and after OD1.

\section{References}

478 Abdo H, Calvo-Enrique L, Martinez Lopez J, Song J, Zhang MD, Usoskin D, El Manira A, Adameyko I,

479 Hjerling-Leffler J, Ernfors P. Specialized cutaneous Schwann cells initiate pain sense. Science 365:

$480 \quad 695-699,2019$.

481 Belzer V, Hanani M. Nitric oxide as a messenger between neurons and satellite glial cells in dorsal root ganglia. Glia 67(7):1296-1307, 2019.

Blatt M, Wiseman S, Domany E. Superparamagnetic Clustering of Data. Phys Rev Lett. 76:3251-3254,

4841996.

485 Cao L, McDonnell A, Nitzsche A, Alexandrou A, Saintot PP, Loucif AJC, Brown AR, Young G, Mis M, 486 Randall A, Waxman SG, Stanley P, Kirby S, Tarabar S, Gutteridge A, Butt R, McKernan RM, Whiting P, 487 Ali Z, Bilsland J and Stevens EB. Pharmacological reversal of a pain phenotype in iPSC-derived sensory neurons and patients with inherited erythromelalgia. Sci Trans/ Med 8, 335ra56335ra56, 2016.

Carnevale T. Neuron simulation environment. Scholarpedia 2(6):1378, 2007. 
bioRxiv preprint first posted online Dec. 11, 2019; doi: http://dx.doi.org/10.1101/871236. The copyright holder for this preprint (which was not peer-reviewed) is the author/funder, who has granted bioRxiv a license to display the preprint in perpetuity.

All rights reserved. No reuse allowed without permission.

494 Doi S, Nabetani S, Kumagai S. Complex nonlinear dynamics of the Hodgkin-Huxley equations induced

495 by time scale changes. Biol Cybern. 85 (1): 51-64, 2001.

496 Ermentrout GB, Terman DH. Mathematical Foundations of Neuroscience. New York: Springer, 2010.

497 Garfunkel LC, Kaczorowski JM, Christy C, editors. Pediatric Clinical Advisor. 2nd ed. Philadelphia:

498 Mosby, 2007.

499 Gold C, Henze DA, Koch C, Buzsáki G. On the Origin of the Extracellular Action Potential Waveform: A

500 Modeling Study. J Neurophysiol. 95 (5): 3113-3128, 2006.

501 Hilgen G, Sorbaro M, Pirmoradian S, Muthmann JO, Kepiro IE, Ullo S, Juarez Ramirez C, Puente

502 Encinas A, Maccione A, Berdondini L, Murino V, Sona D, Cella Zanacchi F, Sernagor E and Hennig MH.

503 Unsupervised Spike Sorting for Large-Scale, High-Density Multielectrode Arrays. Cell Reports

504

18(10): 2521-2532, 2017.

505

Khouzam RH. Chronic pain and its management in primary care. South Med J. 93(10):946-945, 2000.

Krouchev NI, Rattay F, Sawan M, Vinet A. From Squid to Mammals with the HH Model through the

507 Nav Channels' Half-Activation-Voltage Parameter. PLoS ONE 10(12): e0143570, 2015.

Lera Ruiz M, Kraus RL. Voltage-Gated Sodium Channels: Structure, Function, Pharmacology, and

Clinical Indications. J. Med. Chem. 58: 7093-7118, 2015.

Maeda E, Robinson HPC, Kawana A. The mechanisms of generation and propagation of synchronized

bursting in developing networks of cortical neurons. J Neurosci. 15 (10): 6834-6845, 1995.

Maertens C, Cuypers E, Amininasab M, Jalali A, Vatanpour H, Tytgat J. Potent modulation of the voltage-gated sodium channel Nav1.7 by OD1, a toxin from the scorpion Odonthobuthus doriae. Mol

Pharmacol. 70 (1): 405-414, 2006. 
bioRxiv preprint first posted online Dec. 11, 2019; doi: http://dx.doi.org/10.1101/871236. The copyright holder for this preprint (which was not peer-reviewed) is the author/funder, who has granted bioRxiv a license to display the preprint in perpetuity. All rights reserved. No reuse allowed without permission.

517 McDonnell A, Schulman B, Ali Z, Dib-Hajj SD, Brock F, Cobain S, Mainka T, Vollert J, Tarabar S,

518 Waxman SG. Inherited erythromelalgia due to mutations in SCN9A: natural history, clinical

519 phenotype and somatosensory profile. Brain 139 (4): 1052-1065, 2016.

520 McDougal RA, Morse TM, Carnevale T, Marenco L, Wang R, Migliore M, Miller PL, Shepherd GM,

521 Hines ML. Twenty years of ModelDB and beyond: building essential modeling tools for the future of

522 neuroscience. J Comput Neurosci. 42(1):1-10, 2017.

523 Motin L, Durek T, Adams DJ. Modulation of human Nav1.7 channel gating by synthetic $\alpha$-scorpion

524 toxin OD1 and its analogs. Channels 10 (2): 139-147, 2016.

525 Newberry K, Wang S, Hoque N, Kiss L, Ahlijanian MK, Herrington J and Graef JD. Development of a

526 spontaneously active dorsal root ganglia assay using multiwell multielectrode arrays. J Neurophysiol.

527 115(6): 3217-3228, 2016.

528 Quian Quiroga R, Nadasdy Z, Ben-Shaul Y. Unsupervised Spike Detection and Sorting with Wavelets

529 and Superparamagnetic Clustering. Neural Comp. 16:1661-1687, 2004.

530 Rush AM, Cummins TR, Waxman SG. Multiple sodium channels and their roles in electrogenesis

531 within dorsal root ganglion neurons. J Physio/ 579 (1): 1-14, 2007.

532 Rush AM, Dib-Hajj SD, Liu S, Cummins TR, Black JA, Waxman SG. A single sodium channel mutation

533 produces hyper or hypoexcitability in different types of neurons. PNAS 103 (21): 8245-8250, 2006.

534 Scroggs RS, Fox AP. Multiple Ca2+ currents elicited by action potential waveforms in acutely isolated

535 adult rat dorsal root ganglion neurons. J Neurosci. 12 (5) 1789-1801, 1992.

536 Serpell M. Anatomy, physiology and pharmacology of pain. Surgery Oxford 24(10): 350-353, 2006.

537 Sigg D. Modeling ion channels: Past, present, and future. J. Gen. Physiol. 144 (1): 7, 2014.

538 Van Hecke O, Torrance N, Smith BH. Chronic pain epidemiology and its clinical relevance. $\mathrm{Br}$ J

539 Anaesth. 111 (1): 13-18, 2013. 
540 Vivekananda U, Novak P, Bello OD, Korchev YE, Krishnakumar DD, Volynski KE, Kullmann DM. Kv1.1

541 channelopathy abolishes presynaptic spike width modulation by subthreshold somatic

542 depolarization. PNAS 114 (9) 2395-2400, 2017.

543 Wilson PG, Stice SS. Development and differentiation of neural rosettes derived from human

544 embryonic stem cells. Stem Cell Reviews 2(1): 67-77, 2006.

545 Zemel BM, Ritter DM, Covarrubias M, Muqeem T. A-Type KV Channels in Dorsal Root Ganglion

546 Neurons: Diversity, Function, and Dysfunction. Front Mol Neurosci. 11: 253, 2018.

\section{Supporting information}

548 S1 Appendix. Equations Appendix. Equations are from the HH model formulation provided by the

549 NEURON software and the Channel Builder GUI

550 (https://www.neuron.yale.edu/neuron/static/docs/chanlbild/main.html). Parameter values are

551 listed in Table 1 and provided with the corresponding figures.

\section{Acknowledgements}

553 Study funded by MRC BH171892. 
bioRxiv preprint first posted online Dec. 11, 2019; doi: http://dx.doi.org/10.1101/871236. The copyright holder for this preprint (which was not peer-reviewed) is the author/funder, who has granted bioRxiv a license to display the preprint in perpetuity. All rights reserved. No reuse allowed without permission.

A
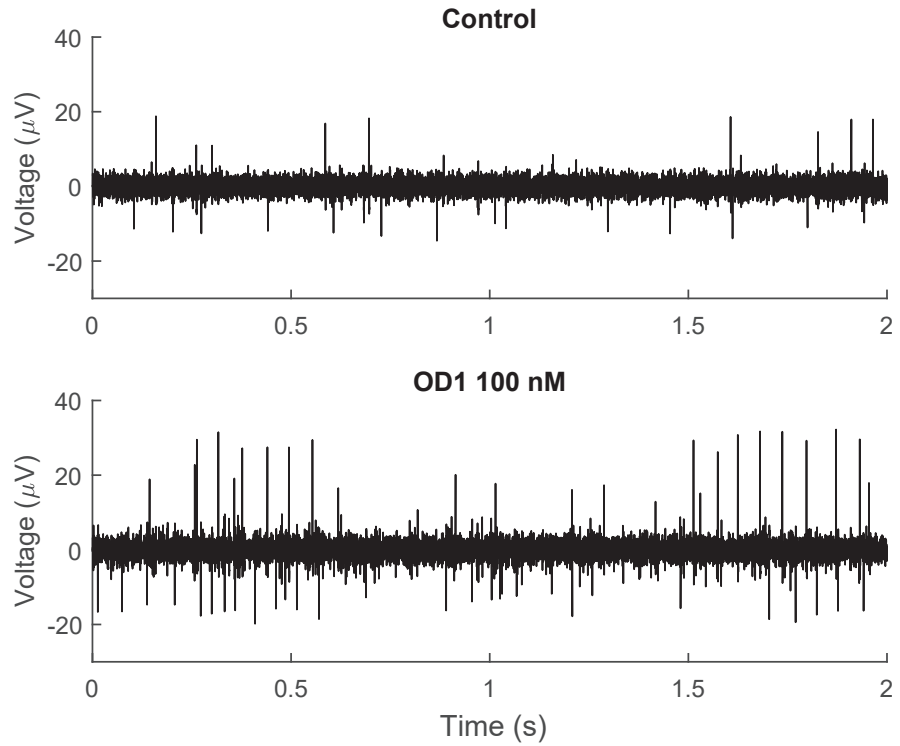

B
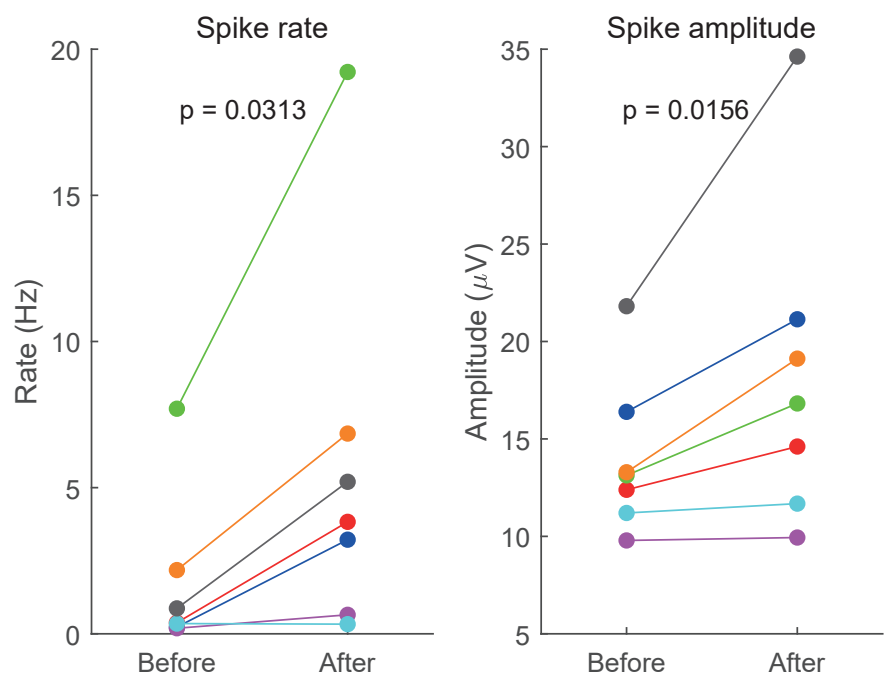


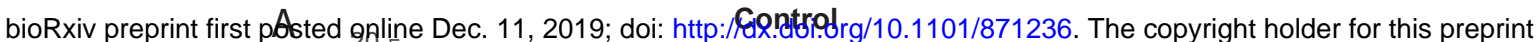
(which was not peer-reviewed) is the author/funder, who has granted bioRxiv a license to display the preprint in perpetuity.
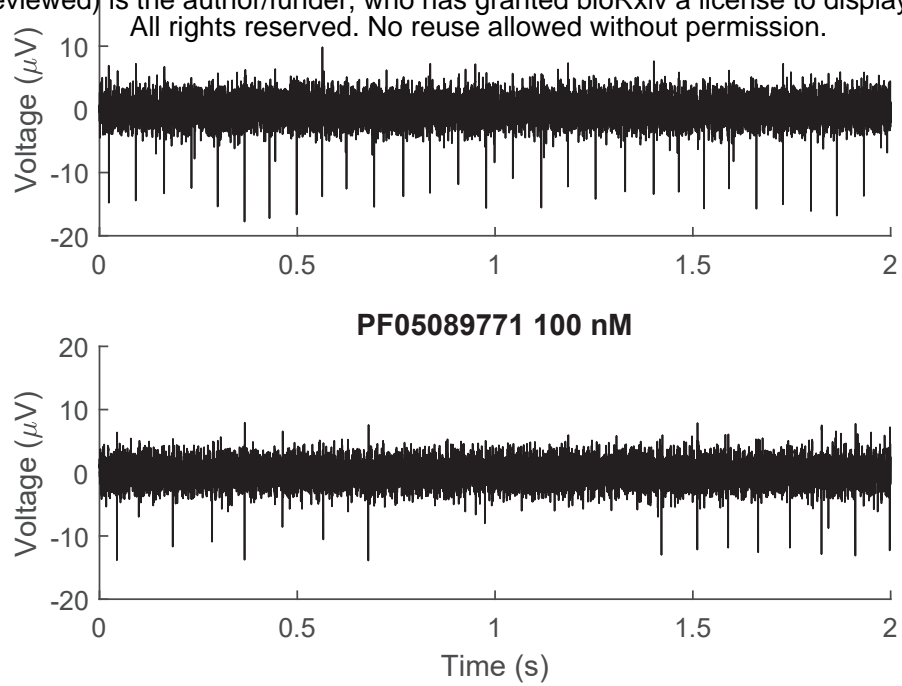

B

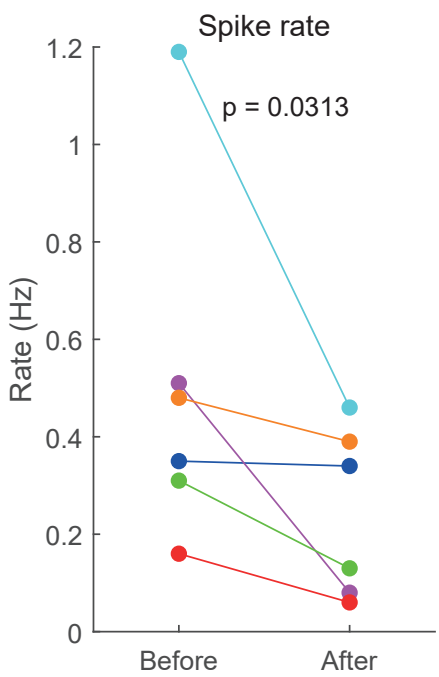

C

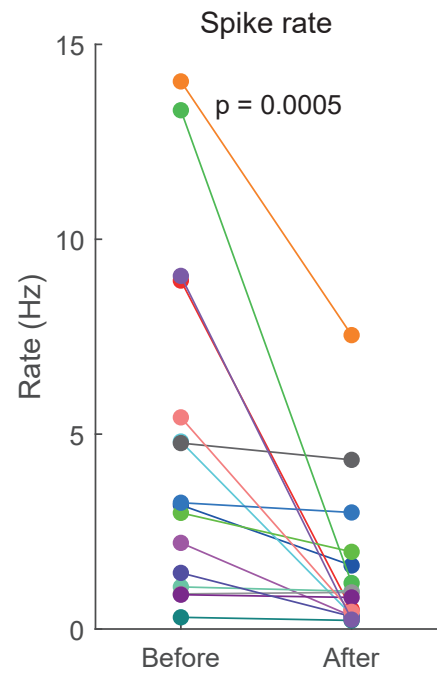

Spike amplitude
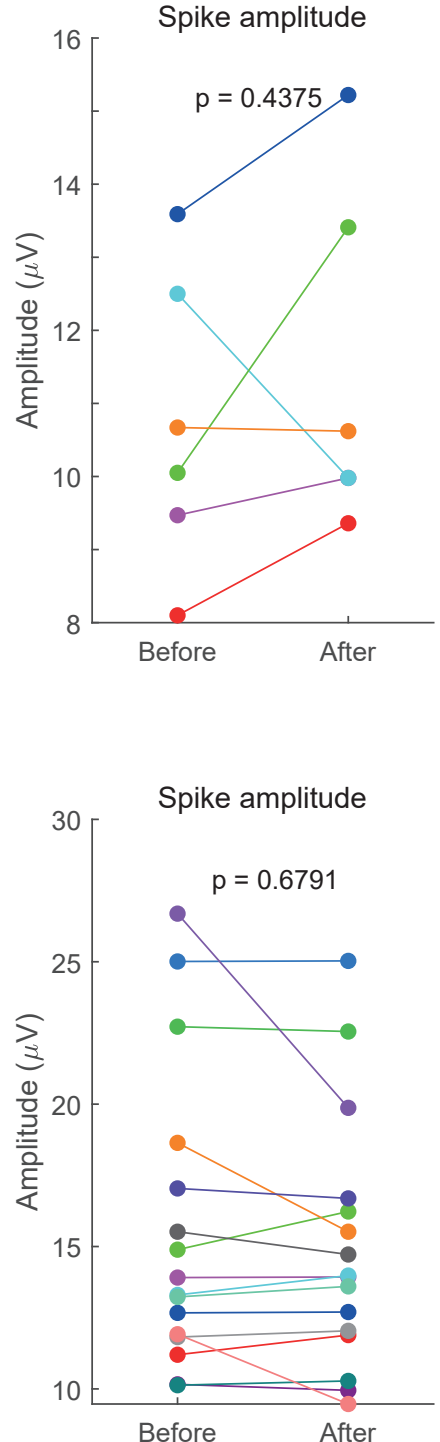
bioRxiv preprint first posted online Dec. 11, 2019; doi: http://dx.doi.org/10.1101/871236. The copyright holder for this preprint (which was not peer-reviewed) is the author/funder, who has granted bioRxiv a license to display the preprint in perpetuity. All rights reserved. No reuse allowed without permission.

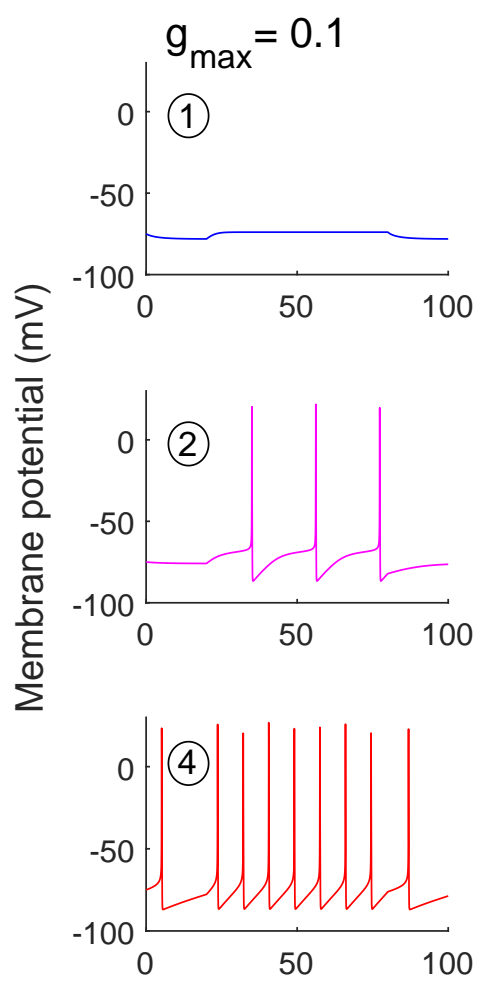

$$
g_{\max }=0.08
$$$$
g_{\text {max }}=0.07
$$$$
d_{m}=-55
$$

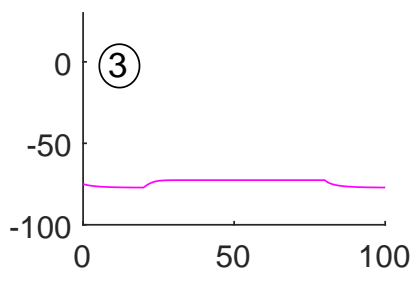$$
d_{m}=-58
$$
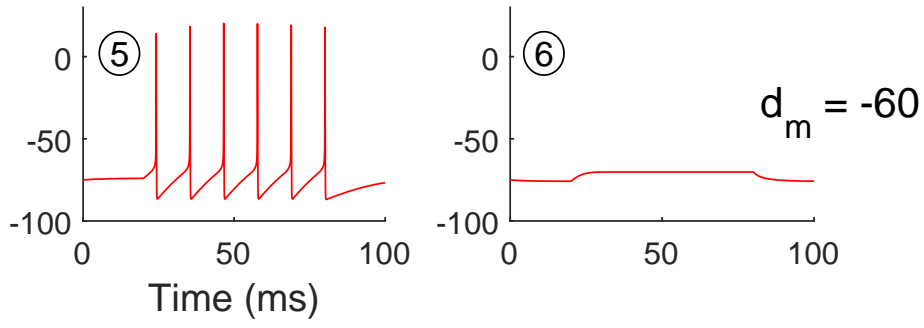


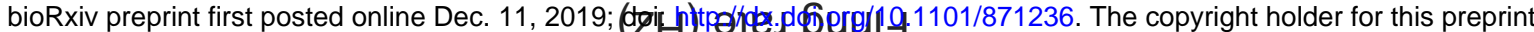
(which was not peer-reviewed) is the author/funder, who has granted bidRxiv a license to display the preprint in perpetuity.
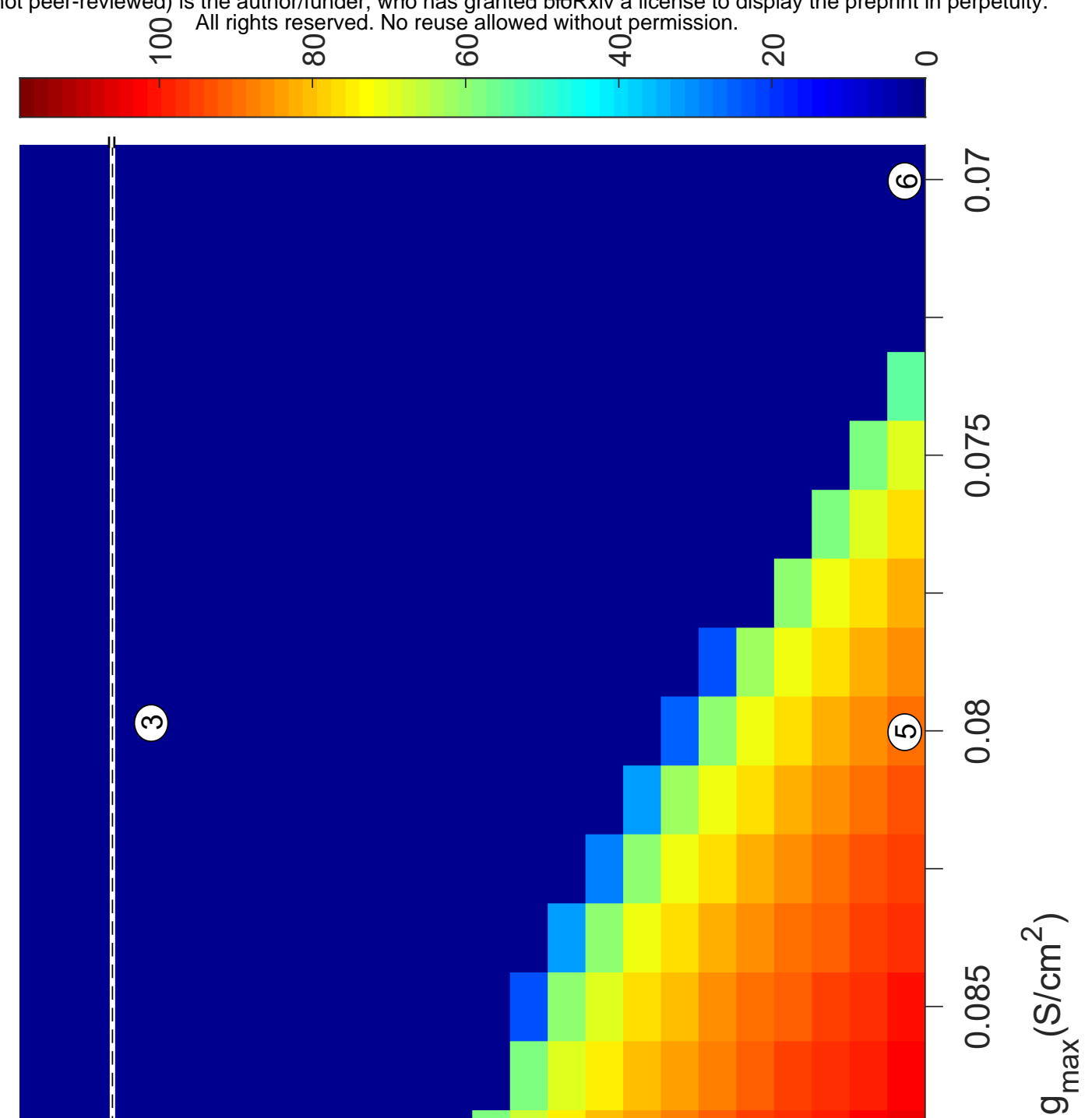

8

ด 
bioRxiv preprint first posted online Dec. 11, 2019; doi: http://dx.doi.org/10.1101/871236. The copyright holder for this preprint (which was not peer-reviewed) is the author/funder, who has granted bioRxiv a license to display the preprint in perpetuity. All rights reserved. No reuse allowed without permission.
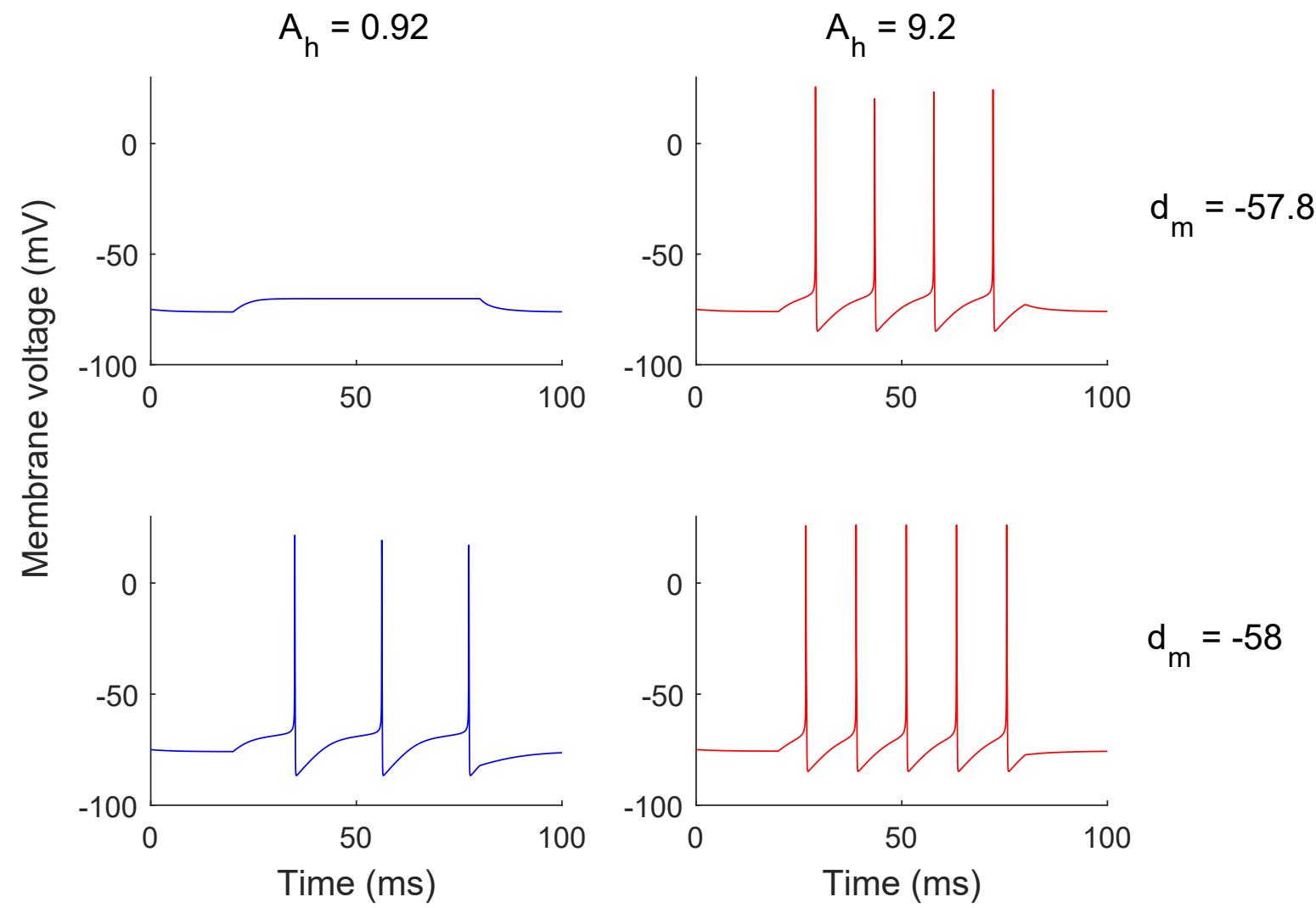
bioRxiv preprint first posted online Dec. 11, 2019; doi: http://dx.doi.org/10.1101/871236. The copyright holder for this preprint (which was not peer-reviewed) is the author/funder, who has granted bioRxiv a license to display the preprint in perpetuity. All rights reserved. No reuse allowed without permission.

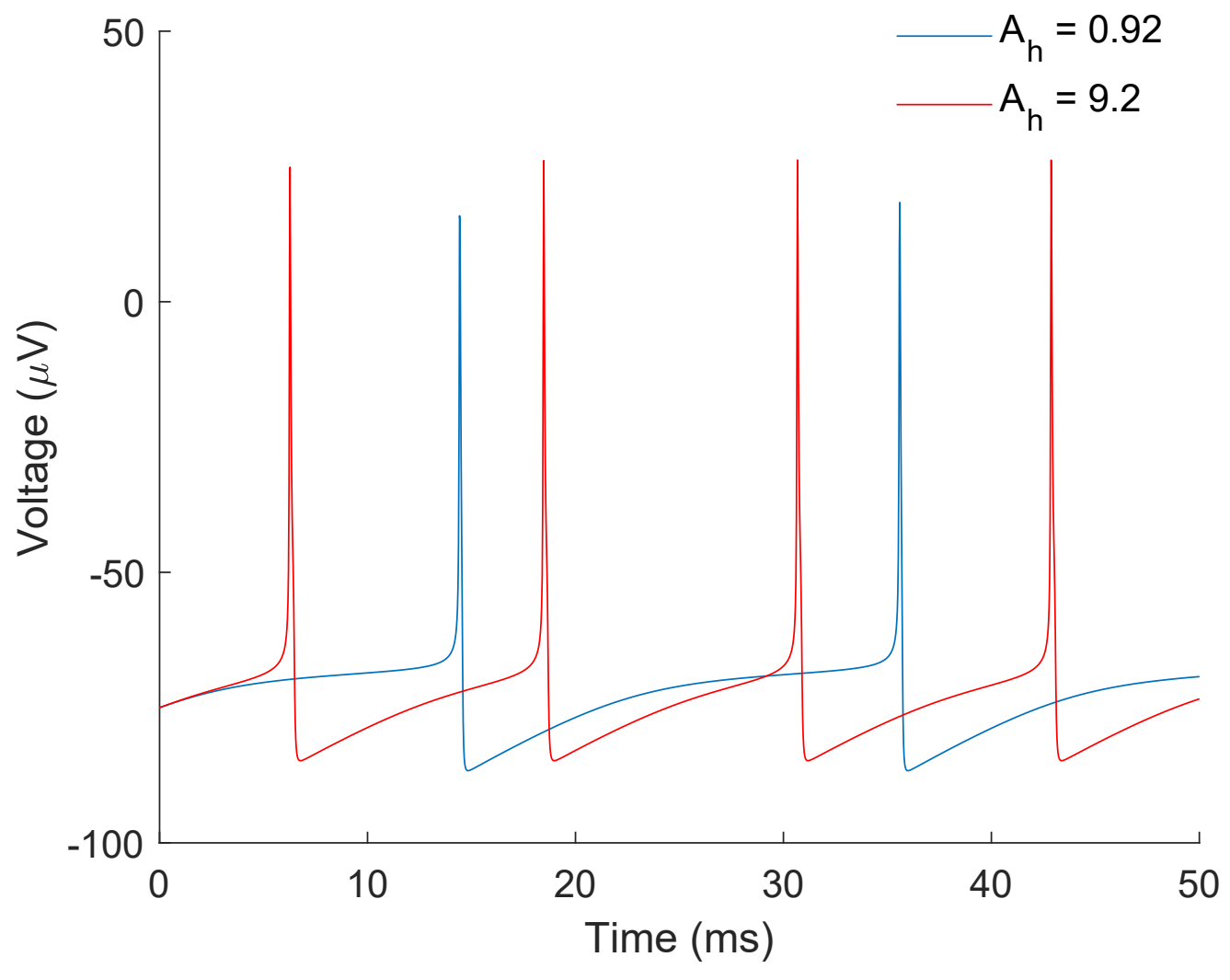


bioRxiv preprint first posted online Dec. 11, 2019; doi: http://dx.doi.org/10.1101/871236. The copyright holder for this preprint (which was not peer-reviewed) is the author/funder, who has granted bioRxiv a license to display the preprint in perpetuity. All rights reserved. No reuse allowed without permission.
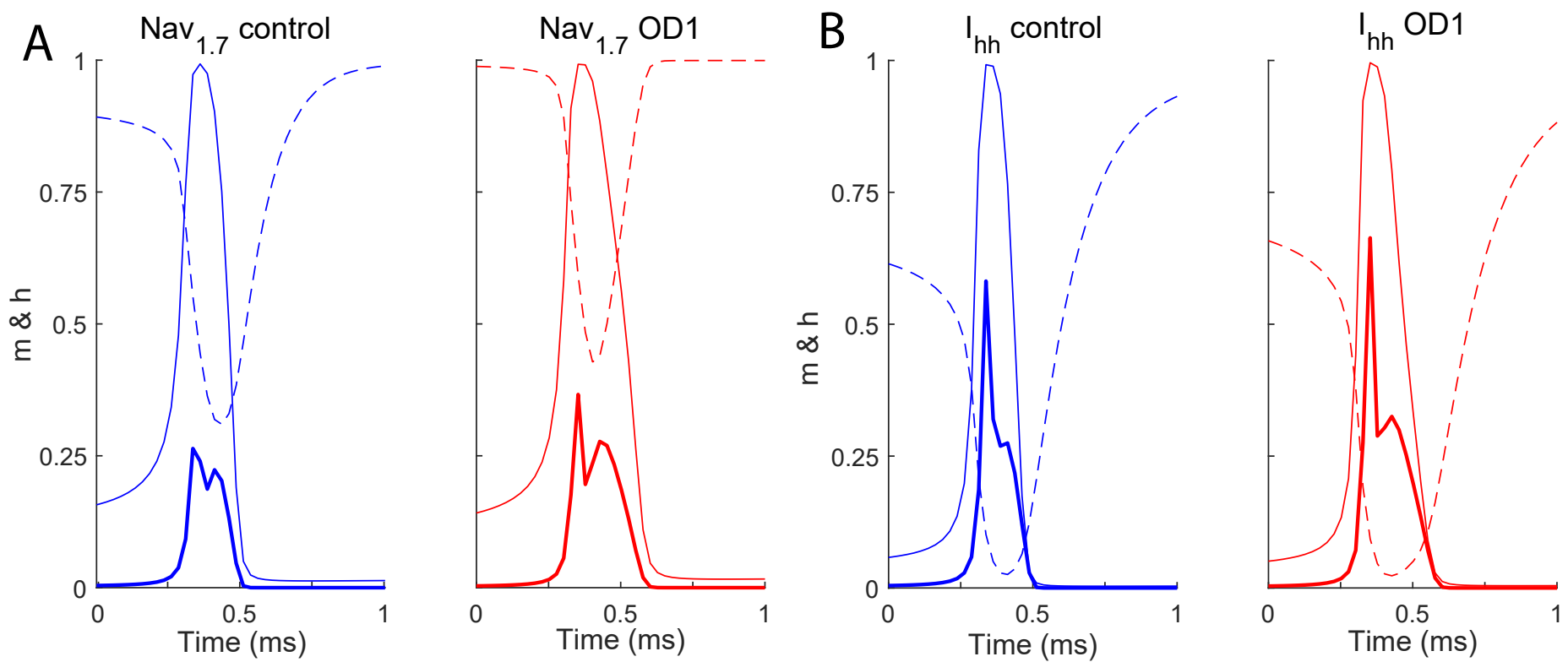